NOTA CIENTÍFICA

\title{
PROPAGAÇÃo VEGETATIVA DE GUACO COM ADIÇÃO DE ÁCIDO NAFTALENOACÉTICO
}

\section{VEGETATIVE PROPAGATION OF GUACO WITH ADDITION OF NAPHTALENE ACETIC ACID}

\author{
Franciely Grose COLODI ${ }^{1}$ \\ Nilton Luiz Ceccon RAMOS ${ }^{1}$ \\ Katia Christina ZUFFELLATO-RIBAS ${ }^{2}$ \\ Luciana Lopes Fortes RIBAS ${ }^{2}$ \\ Henrique Soares KOEHLER ${ }^{3}$
}

\begin{abstract}
RESUMO
O guaco (Mikania glomerata Spr.) é uma planta herbácea nativa da Floresta Atlântica, de grande interesse medicinal e que sofre ações extrativistas. A propagação da espécie é feita por estacas, posta a dificuldade de coleta de sementes. $O$ objetivo deste trabalho foi avaliar o efeito do regulador vegetal ácido naftalenoacético (ANA) no enraizamento de M. glomerata em estaquia semilenhosa. O delineamento experimental foi inteiramente casualizado com seis tratamentos e quatro repetições (10 estacas por tratamento). Foram utilizadas diferentes concentrações de ANA em talco e em solução $(0 ; 2500 ; 5000 \mathrm{mg}$ $\mathrm{kg}^{-1}$ e $0 ; 2500 ; 5000 \mathrm{mg} \mathrm{L}^{-1}$, respectivamente). O experimento foi conduzido entre os meses de agosto e outubro de 2006, em Curitiba-PR. Após 47 dias em casa-de-vegetação, as estacas foram avaliadas com relação ao número de estacas vivas com calos (EC); estacas vivas sem calos (EV); estacas mortas (EM); estacas enraizadas (EE); número de raízes por estaca (NRE) e comprimento das três maiores raízes por estaca (CRE), além do número de estacas com brotações (BR). A mortalidade das estacas foi pequena ( $3 \%$ ) e $20 \%$ das estacas brotaram. A taxa de enraizamento foi alta $(\sim 90 \%)$ em todos os tratamentos, destacando-se o tratamento na concentração de $2500 \mathrm{mg} \mathrm{kg}^{-1}$ de ANA em forma de talco para indução de maior número de raízes por estaca.
\end{abstract}

Palavras-chave: Mikania glomerata Spr.; estaquia semilenhosa; auxina sintética.

\begin{abstract}
The medicinal species Mikania glomerata Spr. (guaco) is native of Atlantic Forest and undergoes non-regulated extraction. Guaco's seeds are rare, so its vegetative propagation occurs by cutting. The aim of this work was to estimate the role of naphtalene acetic acid (NAA) in root induction of $M$. glomerata cuttings. The experiment was installed by entire random with six treatments and four replications (10 cuttings per treatment). The treatments consisted of different NAA concentrations in powder and watersolution $\left(0 ; 2500 ; 5000 \mathrm{mg} \mathrm{kg}^{-1}\right.$ and 0;2500; $5000 \mathrm{mg} \mathrm{L}^{-1}$, respectively). During August and October, 2006 , cuttings were kept in a greenhouse $\left(25{ }^{\circ} \mathrm{C} \pm 2{ }^{\circ} \mathrm{C}, 95 \% \mathrm{RH}\right)$ in Curitiba-PR. The parameters evaluated after 47 days were: cuttings survival with callus (EC); cuttings survival without callus (EV); cuttings dead (EM); cuttings rooted (EE); number of roots per cuttings (NRE); average length of the three longest roots (CRE); cuttings sprouted (BR). Death rate was low ( 3\%) and $20 \%$ of cuttings sprouted. All treatments presented high roots rate $(\sim 90 \%)$, but the powder treatment with $2500 \mathrm{mg} \mathrm{kg}^{-1}$ NAA showed better results for number of roots per cuttings.
\end{abstract}

Key-words: Mikania glomerata Spr.; semihardwood cutting; synthetic auxin.

\footnotetext{
${ }^{1}$ Graduandos do curso de Ciências Biológicas, Universidade Federal do Paraná, Centro Politécnico, Setor de Ciências Biológicas, Curitiba-PR. E-mail: francolodi@hotmail.com

2 Bióloga, Dra., Profa. Associada do Departamento de Botânica, UFPR. E-mail: kazu@ufpr.br

${ }^{3}$ Engenheiro Florestal, Dr., Prof. Associado do Departamento de Fitotecnia e Fitossanitarismo, UFPR.
} 


\section{INTRODUÇÃO}

O gênero Mikania reúne cerca de 415 espécies distribuídas principalmente na América Central e do Sul, sendo 171 espécies citadas no Brasil (RITTER et al., 1992). Mikania glomerata Spr. (Asteraceae) é conhecida popularmente como guaco, coração de Jesus, guaco-liso, guacocheiroso, cipó-caatinga e erva de cobra. A planta caracteriza-se como um sub-arbusto trepador, com abundância de ramos castanho-esverdeados, cilíndricos, lenhosos e estriados. Esta espécie é amplamente distribuída no país, desde a Bahia até Santa Catarina (NEVES e SÁ, 1991).

Estudos desenvolvidos junto a Central de Medicamentos (CEME) comprovaram a ação clínica expectorante do guaco (FIGUEIRA et al., 1991). Além de propriedades expectorante e balsâmica das vias respiratórias, a planta possui, ainda, odor aromático agradável que lembra a baunilha, sendo mantido nos extratos, que são empregados também no preparo de licores, balas e pirulitos, como corretivos de sabor e odor (OLIVEIRA et al., 1984, 1985). O extrato alcoólico de $M$. glomerata apresenta cumarinas, esteróides e triterpenóides; o extrato aquoso aponta a presença de taninos condensados e hidrolisados, glicosídeos saponínicos e ácidos voláteis (LIMA, 2001).

Pela sua grande procura e interesse, aliada às evidentes propriedades medicinais, o guaco é uma das 102 espécies comercializadas pela Associação de Extratores e Produtores de Plantas Medicinais (AEPAM) na região do Vale do Ribeira (NEGRELLE, 1998); também há registros da comercialização em Curitiba e na região litorânea. De acordo com os estudos realizados no litoral do Paraná, muitas das espécies comercializadas são nativas da Floresta Atlântica e encontradas em remanescentes florestais, não havendo evidências de grandes áreas de produção destas, o que constitui indícios de atividade extrativista. Segundo LIMA (1996) e NEGRELLE (1998), o cultivo e atividade extrativista do guaco carecem de dados autoecológicos, informações sobre o estoque natural, ciclos naturais de produção ou cultivo em ampla escala e respostas à extração. Portanto, estudos de espécies nativas da Floresta Atlântica tornam-se imprescindíveis para conservação da biodiversidade, agregando subsídios para o cultivo de espécies de interesses medicinal e econômico.

Em adição aos estudos de composição química e morfodiagnose de $M$. glomerata realizados por OLIVEIRA et al. (1984, 1985), estudos de macro e micropropagação vêm sendo desenvolvidos para o guaco, posta a floração irregular ou inexistente da espécie. Ramos semilenhosos com um par de folhas inteiras são ideais para estabelecimento das mudas de guaco (NEGRELLE e DONI, 2001; LIMA et al., 2003a). No que diz respeito ao substrato, LIMA et al. (2003b) recomendam a casca de arroz carbonizada, sob irrigação diária manual, uma vez que, o guaco é mais exigente em aeração do substrato do que umidade. A nebulização deixaria o substrato muito mais úmido do que aerado.

Estudos de facilidade no desenvolvimento de raízes adventícias em quatro fases de desenvolvimento dos ramos de guaco (estacas de ponteiro, herbáceas, semilenhosas e lenhosas) mostram que todas as fases apresentaram potencial estrutural para desenvolver raízes (BOEGER et al., 2004). Mas para a maior promoção do sistema radicial e produção da espécie com fins comerciais, BOEGER et al. (2004) recomendam a utilização de caules jovens e adição de reguladores vegetais.

Este estudo teve por objetivo avaliar o efeito do regulador vegetal ácido naftalenoacético no enraizamento das estacas de $M$. glomerata em estaquia semilenhosa e agregar informações tecnológicas para a produção de mudas de guaco em maior escala.

\section{MATERIAL E MÉTODOS}

O experimento foi realizado em casa-devegetação climatizada ( $25 \pm 2{ }^{\circ} \mathrm{C}, 95 \%$ UR) da UFPR, no Campus III, Centro Politécnico, em Curitiba (PR), durante os meses de agosto a outubro de 2006.

A espécie foi identificada pelo Dr. Armando Carlos Cervi (Professor do Departamento de Botânica da UFPR) e depositada no herbário do Departamento de Botânica - UFPR, sob o número UPCB-57382 - Mikania glomerata Spr.

As estacas de Mikania glomerata foram retiradas de ramos com flores incipientes coletados de apenas uma planta matriz, em agosto de 2006, localizada em região urbanizada de Curitiba, plantada em pleno sol (25 $29^{\prime} 28,21^{\prime \prime} \mathrm{S}$ e $49^{\circ} 18^{\prime}$ $12,25 " \mathrm{O}$ Gr.). A coleta foi realizada ao final da tarde e os ramos conservados em água até a instalação do experimento na manhã seguinte.

As estacas foram retiradas da parte mediana dos ramos, tendo em média $6,1 \mathrm{~mm}$ de diâmetro, entre 8 a $12 \mathrm{~cm}$ de comprimento e um nó na parte superior, onde foi deixado um par de folhas, sendo cada uma cortada pela metade. Cada estaca teve a parte superior cortada transversalmente e a parte inferior cortada em bisel. Após desinfestação com hipoclorito de sódio a $0,5 \%$ por $15 \mathrm{~min}$ as estacas foram plantadas em tubetes de $53 \mathrm{~cm}^{3}$ de volume, tendo vermiculita de granulação média como substrato e acondicionadas em casa-devegetação climatizada.

Os tratamentos foram compostos por três diferentes concentrações do regulador vegetal ácido naftalenoacético (ANA) aplicado na base das estacas, em forma de talco $\left(0 ; 2500 ; 5000 \mathrm{mg} \mathrm{kg}^{-1}\right) \mathrm{e}$ em solução $\left(0 ; 2500 ; 5000 \mathrm{mg} \mathrm{L}^{-1}\right)$. Para a aplicação do regulador vegetal em solução, as bases das estacas permaneceram por 10 segundos na solução antes de serem plantadas.

Os tratamentos foram submetidos ao delineamento inteiramente casualizado com seis tratamentos e quatro repetições (10 estacas por tratamento, totalizando 240 estacas). Após 47 dias da instalação do experimento, as estacas foram avaliadas quanto ao estabelecimento de mudas, 
analisando-se as seguintes características: número de estacas vivas com calos (EC); estacas vivas sem calo (EV); estacas mortas (EM); estacas enraizadas (EE); número de raízes por estaca (NRE) e comprimento das três maiores raízes por estaca (CRE), além do número de mudas com brotações (BR). Os comprimentos das raízes foram medidos com o auxílio de uma régua milimetrada. A análise estatística dos dados foi realizada no programa MSTAT ${ }^{\circledR}$. As variâncias dos tratamentos foram testadas quanto a sua homogeneidade pelo teste de Bartlett, seguida de análise de variância. As diferenças estatísticas entre as médias dos tratamentos na análise de variância foram comparadas pelo teste Tukey ao nível de $5 \%$ de probabilidade.

\section{RESULTADOS E DISCUSSÃO}

A média de enraizamento das estacas foi de $90 \%$, não havendo diferença estatística quanto à forma de aplicação do regulador vegetal (Tabela 1). A vermiculita de granulação média mostrou-se um bom meio para a propagação vegetativa do guaco, propiciando um substrato aerado.

TABELA 1 - Efeito das diferentes concentrações de ácido naftalenoacético administrado em talco e em solução nas estacas de Mikania glomerata enraizadas, estacas vivas sem calos, estacas vivas com calos, estacas mortas, número de raízes por estaca, comprimento das três maiores raízes e estacas com brotação. UFPR, Curitiba-PR, 2006.

\begin{tabular}{|c|c|c|c|c|c|c|c|}
\hline \multirow{2}{*}{$\begin{array}{l}\text { Tratamentos } \\
\text { ANA }\left(\mathrm{mg} \mathrm{kg}^{-1}\right)\end{array}$} & \multicolumn{7}{|c|}{ Variáveis } \\
\hline & $\begin{array}{l}\mathrm{EE} \\
(\%)\end{array}$ & $\begin{array}{l}\text { EV } \\
\text { (\%) }\end{array}$ & $\begin{array}{l}\text { EC } \\
(\%)\end{array}$ & $\begin{array}{l}\text { EM } \\
(\%)\end{array}$ & NRE & $\begin{array}{l}\text { CRE } \\
(\mathrm{cm})\end{array}$ & $\begin{array}{l}\text { BR } \\
\text { (\%) }\end{array}$ \\
\hline 0 & $90,0 \mathrm{a}$ & 0,0 & 10,0 & 0,0 & $25,7 b$ & $6,5 \mathrm{a}$ & $30,0 \mathrm{a}$ \\
\hline 2500 & $97,5 \mathrm{a}$ & 0,0 & 0,0 & 2,5 & $53,2 \mathrm{a}$ & $3,7 \mathrm{a}$ & $12,8 \mathrm{a}$ \\
\hline 5000 & $77,5 \mathrm{a}$ & 0,0 & 20,0 & 2,5 & $40,2 \mathrm{ab}$ & $3,5 \mathrm{a}$ & $15,8 \mathrm{a}$ \\
\hline \multicolumn{8}{|l|}{ ANA $\left(\mathrm{mg} \mathrm{L}^{-1}\right)$} \\
\hline 0 & $85,0 \mathrm{a}$ & 2,5 & 5,0 & 7,5 & $19,1 \mathrm{~b}$ & $6,0 \mathrm{a}$ & $27,0 \mathrm{a}$ \\
\hline 2500 & $95,0 \mathrm{a}$ & 0,0 & 0,0 & 5,0 & $40,8 a b$ & $5,4 \mathrm{a}$ & $18,4 \mathrm{a}$ \\
\hline 5000 & $95,0 \mathrm{a}$ & 0,0 & 5,0 & 0,0 & $40,8 a b$ & $5,3 \mathrm{a}$ & $17,5 \mathrm{a}$ \\
\hline C.V.\% & 14,5 & & & & 30,1 & 31,8 & 74,4 \\
\hline
\end{tabular}

Médias seguidas pela mesma letra nas colunas, não apresentam diferenças significativas entre si a $5 \%$ de probabilidade pelo teste de Tukey. EE - estacas enraizadas; EV - estacas vivas sem calos; EC - estacas vivas com calos; EM - estacas mortas; NRE - número de raízes por estaca; CRE - comprimento das três maiores raízes por estaca; BR - estacas com brotações. Não foram realizadas análises estatísticas para variáveis com valores nulos.

A porcentagem de estacas enraizadas (EE) foi alta em todos os tratamentos (Tabela 1), não havendo diferença estatística entre elas. Entretanto, destacou-se o tratamento com ANA em talco na concentração de $2500 \mathrm{mg} \mathrm{kg}^{-1}$ com $97,5 \%$ de enraizamento. O guaco é citado na literatura como uma espécie de fácil enraizamento. NEGRELLE e DONI (2001) e OLIVEIRA et al. (1985) citam a facilidade de formação de raízes adventícias, bastando para isso o contato de regiões de nós com a terra úmida; indicando a possibilidade de propagação vegetativa da espécie por mergulhia. Isso justifica porque a quantidade de estacas enraizadas não foi alterada, estatisticamente, pela presença do ANA.

Todas as estacas formaram calos ao enraizar. Dentre as estacas que não enraizaram (EV e EC), a formação de calos foi baixa para todos os tratamentos (Tabela 1), com exceção do tratamento com ANA em forma de talco na concentração de 5000 $\mathrm{mg} \mathrm{kg}^{-1}$, que apresentou $20 \%$ de estacas com calos.

Calos são constituídos por muitas células parenquimatosas, resultantes dos novos centros meristemáticos formados, próximos aos feixes vasculares junto ao floema. São as células destes tecidos que podem vir a se diferenciar e formar os primórdios radiciais. No entanto, a formação de raízes adventícias e de calos é independente (ZUFFELLATO-RIBAS e RODRIGUES, 2001). A ocorrência de calos e raízes, simultaneamente, é devida à sua similar dependência interna e de condições ambientais favoráveis.

De acordo com ZUFFELLATO-RIBAS e RODRIGUES (2001), o ácido naftalenoacético (ANA) é mais tóxico que o ácido indolbutírico (AIB), e deve ser utilizado em baixas concentrações. A porcentagem de morte das estacas foi baixa ( $3 \%)$ e não está relacionada com os tratamentos (Tabela 1), logo as concentrações utilizadas não trazem danos por toxidez. É possível que outros fatores extrínsecos tenham causado a morte das estacas, como dessecação do caule e folhas, fato observado na condução do experimento. Talvez isto tenha ocorrido devido à disposição das estacas na casade-vegetação, onde há diferença de intensidade luminosa. No decorrer do dia, no período da tarde, o sol é mais intenso em parte da casa-de-vegetação, o que deve ter aumentado as taxas de transpiração das folhas.

Detectou-se interação significativa entre os tratamentos com ácido naftalenoacético (talco e solução) apenas no número de raízes por estaca (Tabela 1). O número de raízes formadas por estaca (NRE) foi significativamente maior nos tratamentos com a auxina, logo o uso de regulador vegetal promoveu o desenvolvimento do sistema radicial das estacas, concordando com a sugestão de BOEGER et al. (2004). Destacou-se o tratamento com ANA em 
talco na concentração de $2500 \mathrm{mg} \mathrm{kg}^{-1}$.

Estatisticamente, o ácido naftalenoacético não influencia o comprimento das raízes formadas (CRE) (Tabela 1), porém a média do comprimento das raízes foi maior nos tratamentos aos quais não foi adicionado o regulador vegetal $(6,5 \mathrm{~cm}$ e $6,0 \mathrm{~cm}$ em talco e em solução, respectivamente). Ao se comparar a média do comprimento das raízes (CRE), os tratamentos realizados com ANA em solução $(5,3 \mathrm{~cm})$ foram mais eficientes do que em talco $(3,6 \mathrm{~cm})$, pois o regulador vegetal em solução pode ser transportado pelos tecidos de maneira mais eficaz.

Os tratamentos com o regulador $(2500,5000$ $\mathrm{mg} \mathrm{kg}^{-1}$ e 2500, $5000 \mathrm{mg} \mathrm{L}^{-1}$ ) apresentaram os maiores números de raízes (NRE) e os menores comprimentos de raízes ( $C R E$ ), enquanto os tratamentos sem regulador $\left(0 \mathrm{mg} \mathrm{kg}^{-1}\right.$ e $\left.0 \mathrm{mg} \mathrm{L}^{-1}\right)$ mostram o oposto: menor número de raízes (NRE) e maiores comprimentos de raízes (CRE). Isso indica o direcionamento de reservas para a produção de mais raízes adventícias ao invés do alongamento das raízes já existentes, nos tratamentos com ANA.

O número de brotações (BR) também foi avaliado ( 20\%), mas estatisticamente não foram observadas diferenças significativas. A porcentagem de estacas com brotações foi maior onde não houve adição da auxina, onde também foi menor o número de raízes por estaca. Assim a distribuição das reservas para a formação de brotações não foi desviada para a promoção radicial, como deve ter ocorrido nos casos em que foi adicionado o ANA.

Fazem-se necessários estudos com maior representatividade genética da espécie, pois o material biológico utilizado no presente experimento foi coletado de apenas uma planta matriz. Estudos com indivíduos não permitem extrapolações para a espécie, posto que cada indivíduo pode apresentar respostas diferenciadas aos tratamentos.

\section{CONCLUSÕES}

Nas condições em que foi realizado o presente experimento, pode-se concluir que o enraizamento de Mikania glomerata não depende da aplicação de ácido naftalenoacético, pois as estacas apresentaram alta porcentagem de enraizamento ( 90\%) sem a aplicação do regulador vegetal. Porém, a aplicação de ANA, tanto em solução quanto em talco promove indução de maior número de raízes por estaca.

\section{AGRADECIMENTOS}

Agradecemos ao Dr. Armando Carlos Cervi (Professor do Departamento de Botânica da UFPR) pela identificação do material botânico e ao auxílio de Raphael Yamada e João Paulo Linderman de Sousa na instalação e avaliação do presente experimento.

\section{REFERÊNCIAS}

1. BOEGER, M.R.T.; ALQUINI, Y.; NEGRELLE, R.R.B. Características anatômicas da região nodal de estacas em diferentes fases de desenvolvimento de guaco (Mikania glomerata Sprengel - Asteraceae) e formação de raízes adventícias. Revista Brasileira de Plantas Medicinais, v. 6, n. 2, p. 1-6, 2004.

2. FIGUEIRA, G.M.; MONTANARI JUNIOR, I.; MAGALHÃES, P.M.; PEREIRA, B.; ARCHÂNGELO JUNIOR, U. Técnicas de cultivo de guaco (Mikania glomerata Spreng.). Horticultura Brasileira, v. 9, n. 1, p. 37, 1991. (Resumo do XXXI Congresso Brasileiro de Olericultura).

3. LIMA, R.X. Estudos etnobotânicos em comunidades continentais da área de proteção ambiental de Guaraqueçaba-Paraná-Brasil. Curitiba, 1996. 123 f. Dissertação (Mestrado em Engenharia Florestal) - Curso de Pós-Graduação em Engenharia Florestal, Setor de Ciências Agrárias, Universidade Federal do Paraná.

4. LIMA, N. P. Estaquia semilenhosa e comparação de metabólitos secundários em Mikania glomerata Sprengel e Mikania laevigata Schultz Bip ex Baker. Curitiba, 2001. 88 f. Dissertação (Mestrado em Produção Vegetal) - Curso de Pós-graduação em Agronomia, Setor de Ciências Agrárias, Universidade Federal do Paraná.

5. LIMA, N.P.; BIASI, L.A.; ZANETTE, F.; NAKASHIMA, T. Estaquia semilenhosa e análise de metabólitos secundários de guaco (Mikania glomerata Sprengel e Mikania laevigata Schultz Bip ex Baker). Revista Brasileira de Plantas Medicinais, v. 5, n. 2, p. 47-54, 2003a.

6. LIMA, N.P.; BIASI, L.A.; ZANETTE, F.; NAKASHIMA, T. Produção de mudas por estaquia de duas espécies de guaco. Horticultura Brasileira, v. 21, n. 1, p. 106-109, 2003b.

7. NEGRELLE, R.R.B.; DONI, M.E. Efeito da maturidade dos ramos na formação de mudas de guaco por meio de estaquia. Horticultura Brasileira, v. 19, n. 3, p. 219-222, 2001.

8. NEGRELLE, R.R.B. Exploração e comércio de produtos vegetais não madeiráveis: o caso das plantas medicinais. In: LIMA, R.E.; NEGRELLE, R.R.B. Meio ambiente e desenvolvimento do litoral do Paraná: diagnóstico. Curitiba: Editora da UFPR, 1998. p. 83-92.

9. NEVES, L.J.; SÁ, M.F.A. Contribuição ao estudo das plantas medicinais Mikania glomerata Spreng. Revista Brasileira de Farmácia, v. 72, n. 2, p. 42-47, 1991.

10. OLIVEIRA, F.; ALVARENGA, M.A.; AKISUE, G.; AKISUE, M.K. Isolamento e identificação de componentes químicos de Mikania glomerata Sprengel e de Mikania laevigata Schultz Bip, ex Baker. Revista de Farmácia e Bioquímica da Universidade de São Paulo, v. 20, n. 2, p. 169-183, 1984.

11. OLIVEIRA, F.; AKISUE, G.; AKISUE, M.K.; MANCINI, B.; CHUMZUM, M. Morfodiagnose de Mikania glomerata SprengelCompositae. Revista de Ciências Farmacêuticas, v. 7, p. 17-26, 1985.

12. RITTER, M.R.; BAPTISTA, L.R.M.; MATZENBACHER, N.I. Asteraceae. Gênero Mikania Willd. Seccões Globosae e Thyrsigerae. Flora llustrada do Rio Grande do Sul, n, 21. Boletim do Instituto de Biociências, n. 50, p. 1-90, 1992.

13. ZUFFELLATO-RIBAS, K.C.; RODRIGUES, J.D. Estaquia: uma abordagem dos principais aspectos fisiológicos. Curitiba: [K.C. Zuffellato-Ribas], 2001. 39 p. 
